\title{
Irrational Beliefs among Jordanian College Students and Relationship with Self-Confidence
}

\author{
Dr. Emad Muhammad Al- Salameh \\ Special Education Department, Princess Rahma University College \\ Al- Balqa' Applied University, Jordan \\ E-mail: imad_alsalameh@yahoo.com
}

Received: September 3, $2010 \quad$ Accepted: November 8, $2010 \quad$ doi:10.5539/ass.v7n5p137

\begin{abstract}
This study aims to investigate the irrational beliefs among Jordanian college students and relationship with self-confidence. To fulfill this, (500) students were randomly chosen from Al-Balqa' Applied University in Jordan. Results of the study may be summarized as follows: There was a statistically significant counterproductive relationship between irrational beliefs and self-confidence, There was a statistically significant effect of gender and educational level on the irrational belief; males and first year students were more acceptable to irrational beliefs, and There was a statistically significant effect of gender and educational level on self-confidence level in favor of females and fourth year students.
\end{abstract}

Keywords: Irrational beliefs, Self-confidence, Jordanian college students

\section{Introduction}

More recently, the educational psychology and counseling research have been specifically focused on cognitive and emotional aspects of personality development and role in psychological and social accommodation. In this context, studies researched the role irrational belief mechanisms in the development of emotional and behavioral disorders (Koompaus et al, 1994). The emotional-rational therapy approach developed by (Ellis, 1962) contributed to explanation of the relationship between one's irrational beliefs and emotional ad behavioral disorders. Ellis (1962) proposed that irrational beliefs are the main factor causing emotional and behavior disorders. Depending on Ellis (1962) troubles experienced by an individual are not caused by specific conditions r events; rather they are caused by one's explanation and evaluation of such events and conditions.

In his Emotional-Rational theory, Ellis (1962) stresses that humans have innate predisposition to rational thinking. During early childhood years, an individual will be more influenced by his parents, and other significant figures in forming his own beliefs and thinking. The rational beliefs, therefore, develop early of the age through one's seek for acceptance from others. It is further argued that beliefs, feelings, and acts are both influence and being influenced by each other.

Ellis has differentiated between (rational beliefs) and (irrational beliefs) arguing that rational-thinking persons tend to be relative in their judgments and evaluations using mostly such words as maybe, possible, probably.., etc. This way of perception and visualization creates in them self-consistency and adaptability to reality which will lead to feelings of consent, efficacy, comfort, and stability. Irrational-thinking persons tend mostly to make absolute and resolved judgments and most often use such words as must, should be, ought to be, supposed to be.., etc. Such judgments and perceptions in most cases contradict with the self and life realities, which add another form of emotional stress like anxiety, depression, and sadness (Dryden, 1999).

\subsection{Self-Confidence}

Self-confidence has much to do with personality development, and psychological stability. Self-confidence also associated with well-being, happiness; whereas low levels of self-confidence increase the probability that one will be at risk $\mathrm{f}$ anxiety, tension, and depression. In general, self-confidence is associated with an integer personality, because self-confidence is a significant personality trait that affects one's behavior along different life stages and considered as an indication of normal personality and a feature of psychological and social adaptability (Mruk, 1995; Abouserie, (1994). Self-confidence develops at early childhood years when parent reactions play a significant role in developing the sense of self-confidence in a child (Paterson, 1987). The sense 
of inferiority and low self-confidence are two main contributors to psychological disorders in individuals. However, self-confidence is a major component of self-concept and both are strongly associated as one who has positive self-concept will have high self-confidence; whereas one who has negative self-concept is predicted to have low self-confidence (McCarty, 1988; McCoby, 1992; Woldfradt et al., 1988).

\subsection{Prior Studies}

Results from prior studies were varied regarding effect of gender on the irrational beliefs. Many studies reported differences among males and females on the irrational beliefs (Daly \& Burton, 1983; Zwemer \& Deffenbacher, 1984; McLennan, 1987; Marcotte, 1966; Bridges \& Roig, 1997; Al-Rehani, 1987; Al-Mousawi, 2005; and Ghnaim, 2002). However, Jaradat (2006) demonstrated that females were more inclined than males to irrational beliefs. Comparatively, studies addressed the relationship between self-confidence and irrational beliefs indicated a negative relationship between irrational thinking and low self-confidence (Berger, 1974; Berger, 1982; Daly \& Burton, 1983; McLennan, 1987; Jaradat 2006). The literature review revealed varied results regarding effect of gender on self-confidence. For example, Sandsbury (1986) showed that females were self-confident more than males. However, Hall (1990) indicated no differences in self-confidence level attributed to gender. This result is supported by Lenny et. al (1983); whereas Zeigler \& Hiller (2000) reported that females were substantially less self-confident than males.

\section{Significance of the Study}

It is a common belief among educators and psychological councilors that the therapeutic approach is insufficient by itself to improve social and psychological compatibility in learners; rather developmental and preventive approaches are needed to reach highest possible psychological stability. The literature reviewed revealed many studies that confirm the association between irrational beliefs with various forms of emotional disorders such as depression, anxiety, aggressiveness, etc. The literature reviewed showed many studies that investigated the relationship between irrational beliefs and different variables. The present study specifically addresses the relationship between irrational beliefs and self-confidence level and effects on both gender and college level of students. Hopefully, findings from this study would be helpful for educators and other workers in the educational field to reactivate the developmental and preventive approach to boost normal social and emotional growth.

\section{Study Questions}

1. What is the level of irrational beliefs among Jordanian college students?

2. Is there a relationship between irrational beliefs and self-confidence level among Jordanian college students?

3. Are there statistically significant differences in the irrational beliefs attributed to gender and educational level?

4. Are there statistically significant differences in the irrational beliefs attributed to gender and educational level?

\section{Limitations}

- Results from this study would be limited by how valid and reliable are instruments used in this study.

- This study involved a sample of 500-prticipants recruited from Jordanian college students enrolled during the academic year 2009/2010.

\section{Operational Definitions}

\subsection{Irrational Beliefs}

Refers to acceptability of irrational beliefs of a student and measured by the score obtained by student on the irrational beliefs test designed for this purpose.

\subsection{Self Confidence}

Refers to the level of self-confidence and measured by the score obtained by student of the self-confidence scale designed by the researcher.

\section{Method \& Procedures}

\subsection{Population}

Consisted of the whole students attending Al-Balqa' Applied University in Jordan enrolled for the academic year 2009/2010 


\subsection{Sample}

500 students participated in the current study and selected by simple random method from among Al-Balqa' Applied University in Jordan. Table (1) shows participant characteristics.

\section{Instruments}

\subsection{Self-Confidence Scale}

By reviewing a number of self-confidence scales and how they were designed, the researcher developed the Self-Confidence Scale used in the present study. The instrument included 40-items and based on their content were assigned to positive $(n=15)$ and negative $(n=25)$ items. The scale was three-point Likert-type scale ranging from $(3=$ mostly, $2=$ sometimes, $1=$ rarely) representing negative items. Validity was ensured by sending the scale to a number of experts and making necessary adjustments in accordance with their comments. However, reliability $(\mathrm{r}=0.94)$ was measured using test-retest method. The scale was administered to a pilot sample $(\mathrm{n}=60)$ chosen out of the original sample. The scale was re-administered to the same sample two weeks later.

\subsection{Rational/Irrational Beliefs Scale}

Al-Rehani (1985) developed and standardized the rational/irrational beliefs scale to fit the Jordanian environment. This scale has 52 -items measuring thirteen irrational dimensions, eleven originally stressed by Elis in his theory and two were added by Al-Rehani to fit the Jordanian environment. Items on the scale requires responses of yes $(=1)$, which implies acceptance of the irrational belief or no $(=2)$, which indicate refusal of the irrational belief. The overall degree (104) on the test means acceptance of all irrational beliefs; degree (52) refers to the least degree an examinee would have and implies refusal of all irrational beliefs. The grade of (78) representing the borderline between rationality and irrationality. Grades (4-5) indicate rationality on the sub-dimension, grade (6) indicate ranging between rationality and irrationality, whereas grade (7-8) indicate irrationality on the sub-dimension. The test had reasonable reliability coefficients $(0.45$ and 0.83$)$ using the test-retest method with mean grade $(0.70)$ on the sub-dimensions and overall grade $(0.91)$. The test had high reliability coefficients, with inter-rater agreement was at 90 per cent; in addition to experimental validation and ability to differentiate between normal and psychotic subjects.

\section{Results}

\subsection{Results related to question one}

"What is the level of irrational beliefs among Jordanian college students?" To answer this question, means and standard deviations were computed for grades obtained by participants on the irrational/rational test as shown by table (2).

Table (2) shows that mean grade (82.67) of male participants on the rational/irrational beliefs test was higher than that for the male participants (71.89), meaning that males were more acceptable to irrational beliefs than females. Mean grade (83.30) of first year participants on the rational/irrational beliefs test was higher than for fourth year participants (71.26), indicating the first year students were more acceptable to irrational beliefs than fourth year students.

Mean grades on the rational/irrational beliefs test sub-scales show hesitation between rationality and irrationality regarding large numbers of irrational beliefs excluding the following:

- Irrational belief "Individual must be perfectly effective and achieving to have a value" was acceptable to females (7.02), and to fourth year students (7.06).

- Irrational belief "Some people are badly evils, malicious, and highly despicable that they should be blamed and punished" was acceptable to males (7.00), females (7.01) and first year students (7.02)

- Irrational belief "Past experiences and events determine present conduct, and past could not be escaped" was acceptable to males (7.08) and first year students (7.13)

- Irrational belief "No doubt, man's status is the most important in his relation with a woman" was acceptable to males (7.02) and first year students (7.05)

\subsection{Results related to question two}

Is there a relationship between irrational belief and self-confidence among Jordanian college students?

To answer this question, Pearson correlation (0.465-) was computed between participant overall grade on the rational/irrational scale and their grades on the self-confidence scale. This correlation was found statistically 
significant at (0.001) level, indicating a statistically significant steady relationship between irrational beliefs and self-confidence i.e. the higher the level of self-confidence the lower the irrational belief will be and verse-versa.

\subsection{Results related to question three}

Are there statistically significant differences in irrational belief among Jordanian college students attributed to gender and college level?

To answer this question, means and standard deviations were computed as shown in table (3).

Table (3) shows variance between mean estimates of both males and females and also between mean estimates of first and fourth year students on the rational/irrational test. To check whether such differences were statistical, T-test was conducted and table (4) shows related results.

Table (4) shows a statistically significant effect of gender on the irrational belief meaning existence of statistically significant differences in the irrational belief among male and females with differences being in favor of males as shown by table (3). Similarly, table (4) demonstrates a statistically significant effect of the educational level on the irrational belief, meaning statistically significant differences in the irrational belief among first and fourth year students with differences being in for of first year students as shown by table (3).

\subsection{Results related to question four}

Are there statistically significant differences in self-confidence among Jordanian college students attributed to gender and college level?

To answer this question, means and standard deviations were computed as shown by table (5).

Table (5) shows perceived disparity between mean scores of males versus females, and of fourth year versus first year students on the self-confidence scale. To check whether such differences were statistically significant, t-test was administered and table (6) shows related results.

Table (6) shows a statistically significant effect of gender on self-confidence level, meaning existence of statistically significant differences in self-confidence levels among males and females in favor of females (see table5). Table (6) also shows a statistically significant effect of educational level on self-confidence, implying existence of statically significant differences in self-confidence among first year and fourth year students with differences being in favor of fourth year students (see table 5).

\section{Discussion}

In general speaking, results from the present study demonstrate that Jordanian college students assume an undecided posture ranging between rationality and irrationality. Mean estimates of participants on the subscales were on the borderline between rationality and irrationality. This result can be explained by interplay of the cultural factors and vast variance of experiences maintained by college students inside and outside the campus. It is worth to note that college students, both males and females unanimously agree on the irrational belief "Some people are badly evils, malicious, and highly despicable that they should be blamed and punished", and this attitude would be due the family socialization style that encourages intolerance and negative attitudes to others. This result implies a serious indication that the commonly held irrational beliefs would be the direct cause underlying the college-based violence presently dominating Jordanian universities. In addition, the result indicating that males accept the irrational belief "no doubt that relative to woman, man takes the most significant placement" can be accounted for by the masculine culture of the Jordanian community, which favors males to females and instills in males this irrational preference since childhood years. Results from this study show that females were more adherence to the irrational belief "Individual should be perfectly effective and accomplishing to have a value", which can be due the fact that females in general look for a place in the community by means of achievement and excellence which creates, in them, a compulsive tendency to perfectionism.

Results further indicated a statistically significant effect of gender on the irrational belief. This result is in consistent with Jaradat (2006) that found statistically significant differences in rational beliefs among both males and females; whereas differed with results from other studies (Daly \& Burton, 1983; Zwemer \& Deffenbacher, 1984; McLennan, 1987; Al-Rehani, 987; Marcotte, 1996; and Bridges \& Roig, 1997).

The results also indicated a statistically significant effect of the educational level on the irrational beliefs. It is a commonly perceived that fourth years students.

This result can be due to the open culture and knowledge to which college students are exposed at the university, implying that students at higher level of college will be affected more by such environment. This result is inconsistent with Jaradat (2006). 
Regarding whether there is a relationship between self-confidence and irrational belies, results confirmed a statistically significant inverse correlation between self-confidence and irrational beliefs. Students who are more opened to irrational beliefs are less self-confident, which is reasonable because one who is less self-confident will be occupied with irrational beliefs and verse-versa. This result complies with Jaradat (2006), Berger (1974), Daly \& Burton (1983), and McLennan (1987).

As for gender effect on the self-confidence, results indicated that compared with males, females were more self-confident. This result can be accounted for by Jordanian woman's self-actualization attitude which appeared in response to the discrimination-against-woman dominating the Jordanian culture that is predominantly masculine. This result is consistent with Standbury (1986). In this context, self-confidence among fourth year was higher than among first year students which could be due to the diversified nature of the university life with its various extra-curricular activities, programs, and events that over time support self-confidence.

\section{Conclusion}

The conclusion from the present study is that Jordanian college students, in general, maintain what so-called irrational beliefs crisis. Results demonstrated that Jordanian college students are on the borderline between rationality and irrationality, which is a paramount indication that needs further attention. Specifically, this study confirms an inverse relationship between self-confidence and irrational thinking as leveraging the self-confidence level automatically reduces irrational thinking levels and vice-versa.

In light of results concluded by this study, it is recommended to pay greater attention to emotional aspect of college students in Jordan by offering counseling programs aiming at enhancing their self-confidence and help them adopt more rational approaches in their life, with a greater emphasis being given to first year male students.

\section{References}

Abouserie, R. (1994). Sources and levels of stress in relation to locus of control and self-esteem in university students. Educational Psychology, (14), p. 323-330.

Al-Mousawi, N. (2005). Content Analysis of Irrational Beliefs among Saudi College Students. Educational Journal, 9 (75), p. $91-130$.

Al-Rehani, S. (1985). Developing Rational-Irrational Beliefs Test. Educational Sciences Studies Journal, 12(11), P. 75-95.

Al-Rehani, S. (1987). Irrational Beliefs among University of Jordan's Students and Relationship of Gender and Major with the Irrational Beliefs. Jordanian Studies Journal, 14(5), p. 103-124.

Berger, F. M. (1974). Irrational Self- coinsure: The Problem and its Correction. The Personal and Guidance Journal, (53), p.193-198.

Berger. F. M. (1982). Self- Devaluation in College Students. Journal of Rational living, (17), p. 23-25.

Bridges, K. R \& Roig, M. (1997). Academic procrastination and irrational thinking: A reexamination with context controlled. Personality and Individual Differences, (22), p. 941-944.

Daly, M. J \& Burton, R. L. (1983). Self-esteem and irrational beliefs: An exploratory investigation with implications for counseling. Journal of Counseling Psychology, (30), p. 361-366.

Dryden, W. (1999). Rational emotive behavioral counseling in action. London: Sage.

Ellis, A. (1962). Reason and emotion in psychotherapy. New York: Lyle Stuart.

Ghnaim, M. (2002). Effect of Irrational Beliefs and Major on Teacher's Burn-out: Cross-cultural Study of Egypt and Saudi Arabia. Educational Journal. University of Kuwait, 16(64). p. 175-213.

Ivey, A. E., D’Andrea, M., Ivey, M. \& Simek-Morgan, L. (2002). Theories of counseling and Psychotherapy: A multicultural perspective. Boston: Allyn and Bacon.

Jaradat, A. (2006). Relationship between Irrational Beliefs and Self-Esteem among Jordanian College Students. Jordan Journal of Educational Sciences, 2(3). P143-153.

Koopmons, P. C., Sanderman, R., Timmerman, I. \& Emmelkamp, P. (1994). The Irrational Beliefs Inventory (IBI) Development and Psychology Evaluation. European Journal of Psychological Assessment, (10), p. 15-57.14.

Maccoby, E. (1992). The role of parents in the socialization of children: An historical overview. Developmental psychology, (28), p. 1006-1017. 
Marcotte, D. (1996). Irrational beliefs and depression in Adolescence. Adolescence, (31), p. 935-954.

McCarty, A. (1988). Effects of Feedback on the Self- Confidence of men and women. Academy of management journal, (29), p. 840-847.

McLennan, J.P. (1987). Irrational beliefs in relation to self-esteem and depression. Journal of Clinical Psychology, (43), p. 89-91.

Mruk, C. (1995). Self-esteem: Research, Theory, and Practice. New York: Springer.

Paterson, C. (1987). Theories of Counseling and Psychotherapy. Harper and Row Publishing. Co. New York.

Stansbury-kendy, I. (1986). The relationship of the supportiveness of the academe to the self-confidence and assertiveness in academic work for men and women graduate students in Science and engineering. paper presented at the annual meeting of the American educational research Association. (67th San fannies co).

Wolfradt, U, Hempel, S. \& Miles, J. (2003). Perceived parenting styles, depersonalization, anxiety and coping behavior in adolescents. Personality and individual Differences, (34), p. 521-532.

Woolfolk, A. (2001). Educational psychology. (8th Ed.). Needham Heights, MA: Allyn \& Bacon.

Ziegler, A \& Heller, K. A. (2000). Conditions for self-confidence among boys and girls achieving highly in chemistry. Journal of secondary gifted education, (11), p. 144-151.

Zwemer, W. A. \& Deffenbacher, J. L. (1984). Irrational beliefs, anger, and anxiety. Journal of Counseling Psychology, (31), p. 391-393.

Table 1. Participant characteristics

\begin{tabular}{llll}
\hline $\begin{array}{l}\text { Gender } \\
\text { College Level }\end{array}$ & Males & Females & Total \\
\hline First Year & & & \\
Fourth Year & 125 & 125 & 250 \\
Total & 125 & 125 & 250 \\
\hline
\end{tabular}

Table 2. Means and standard deviations of overall subject estimates on the rational/irrational belief scale and subscales by gender and education

\begin{tabular}{llllll}
\hline \multicolumn{1}{c}{ Irrational Beliefs } & & Variable & & M & SD \\
& & & & \\
\hline Overall Degree & Gender & M & 82.67 & 6.04 \\
& & College Level & First & 71.89 & 8.12 \\
& & & 83.30 & 5.15 \\
& & Fourth & 71.26 & 7.85 \\
It is necessary that one should be acceptable by & Gender & M & 6.21 & 1.51 \\
each of his local environment members & & F & 6.16 & 1.44 \\
& & College Level & First & 6.11 & 1.50 \\
& & Fourth & 6.26 & 1.45 \\
Individual must be perfectly effective and & Gender & M & 6.27 & 5.49 \\
achieving to have a value & & F & 7.02 & 8.71 \\
& & College Level & First & 6.22 & 4.80 \\
Some people are badly evils, malicious, and & \multirow{2}{*}{ Gender } & Fourth & 7.06 & 8.71 \\
highly despicable that they should be blamed & & M & 7.00 & 1.00 \\
& & F & 7.01 & 8.62 \\
\hline
\end{tabular}




\begin{tabular}{|c|c|c|c|c|}
\hline \multirow[t]{2}{*}{ and punished } & \multirow[t]{2}{*}{ College Level } & First & 7.20 & 9.57 \\
\hline & & Fourth & 6.98 & 9.18 \\
\hline \multirow{4}{*}{$\begin{array}{l}\text { It is a frustrating misfortune for one if things } \\
\text { gone contrary to hopes }\end{array}$} & \multirow[t]{2}{*}{ Gender } & M & 5.36 & 8.05 \\
\hline & & $\mathrm{F}$ & 4.45 & 9.06 \\
\hline & \multirow[t]{2}{*}{ College Level } & First & 5.43 & 7.89 \\
\hline & & Fourth & 4.38 & 7.31 \\
\hline \multirow{4}{*}{$\begin{array}{l}\text { One's unhappiness and helplessness result from } \\
\text { externalized uncontrollable conditions }\end{array}$} & \multirow[t]{2}{*}{ Gender } & $\mathrm{M}$ & 6.72 & 1.51 \\
\hline & & $\mathrm{F}$ & 4.77 & 1.34 \\
\hline & \multirow[t]{2}{*}{ College Level } & First & 6.84 & 1.41 \\
\hline & & Fourth & 4.65 & 1.26 \\
\hline \multirow{4}{*}{$\begin{array}{l}\text { Risks and uncertainties elicits great interest and } \\
\text { involvement, so they constantly preoccupies } \\
\text { one's thinking }\end{array}$} & \multirow[t]{2}{*}{ Gender } & M & 5.82 & 1.36 \\
\hline & & $\mathrm{F}$ & 5.24 & 6.05 \\
\hline & \multirow[t]{2}{*}{ College Level } & First & 5.88 & 1.40 \\
\hline & & Fourth & 5.18 & 4.37 \\
\hline \multirow{4}{*}{$\begin{array}{l}\text { It easier to evade a difficulty or duty than } \\
\text { coping it. }\end{array}$} & \multirow[t]{2}{*}{ Gender } & $\mathrm{M}$ & 5.74 & 1.00 \\
\hline & & $\mathrm{F}$ & 5.34 & 7.35 \\
\hline & \multirow[t]{2}{*}{ College Level } & First & 5.77 & 1.03 \\
\hline & & Fourth & 5.31 & 6.69 \\
\hline \multirow{4}{*}{$\begin{array}{l}\text { One should depend on others, and there should } \\
\text { be someone stronger who is dependable }\end{array}$} & \multirow[t]{2}{*}{ Gender } & $\mathrm{M}$ & 6.32 & 1.66 \\
\hline & & $\mathrm{F}$ & 6.17 & 1.31 \\
\hline & \multirow[t]{2}{*}{ College Level } & First & 6.21 & 1.71 \\
\hline & & Fourth & 6.28 & 1.24 \\
\hline \multirow{4}{*}{$\begin{array}{l}\text { Past experiences and events determine present } \\
\text { conduct, and past could not be escaped }\end{array}$} & \multirow[t]{2}{*}{ Gender } & M & 7.08 & 4.59 \\
\hline & & $\mathrm{F}$ & 6.22 & 4.70 \\
\hline & \multirow[t]{2}{*}{ College Level } & First & 7.13 & 4.29 \\
\hline & & Fourth & 6.17 & 3.99 \\
\hline \multirow[t]{4}{*}{ One should sympathize others } & \multirow[t]{2}{*}{ Gender } & M & 5.98 & 8.52 \\
\hline & & $\mathrm{F}$ & 5.38 & 6.30 \\
\hline & \multirow[t]{2}{*}{ College Level } & First & 6.02 & 8.50 \\
\hline & & Fourth & 5.34 & 5.87 \\
\hline \multirow{4}{*}{$\begin{array}{l}\text { There is always an ideal and best solution to } \\
\text { problems that should be sought }\end{array}$} & \multirow[t]{2}{*}{ Gender } & M & 6.15 & 5.43 \\
\hline & & $\mathrm{F}$ & 5.28 & 5.81 \\
\hline & \multirow[t]{2}{*}{ College Level } & First & 6.20 & 5.32 \\
\hline & & Fourth & 5.22 & 4.95 \\
\hline One to have a value should seem serious and & Gender & M & 6.78 & 7.10 \\
\hline sober in dealing with others & & $\mathrm{F}$ & 6.01 & 4.61 \\
\hline & College Level & First & 6.84 & 6.63 \\
\hline & & Fourth & 5.95 & 4.12 \\
\hline No doubt, man's status is the most important in & Gender & M & 7.02 & 6.58 \\
\hline his relation with a woman & & $\mathrm{F}$ & 6.11 & 6.71 \\
\hline & College Level & First & 7.05 & 6.66 \\
\hline & & Fourth & 6.07 & 6.10 \\
\hline
\end{tabular}


Table 3. Participant overall grade estimates on the rational/irrational belief scale by gender and educational level

\begin{tabular}{llll}
\hline & Variable & M & SD \\
\hline Gender & Males & 82.67 & 6.04 \\
& Females & 71.89 & 8.12 \\
\multirow{2}{*}{ College Level } & First Year & 83.30 & 5.15 \\
& Fourth ear & 71.26 & 6.85 \\
\hline
\end{tabular}

Table 4. T-test results comparing differences between participants' mean estimates on the rational/irrational scale by gender and college level

\begin{tabular}{lccl}
\hline Variable & T-Value & Freedom Degrees & $\boldsymbol{\alpha}$ \\
\hline Gender & 16.824 & 498 & 0,007 \\
College level & 20.282 & 498 & 0.000 \\
\hline
\end{tabular}

Table 5. Subject mean estimates on the self-confidence scale by gender and educational level

\begin{tabular}{llll}
\hline Variable & & Mean & SD \\
\hline Gender & M & 70.40 & 8.949 \\
& F & 85.31 & 11.940 \\
College level & First & 69.74 & 8.247 \\
& Fourth & 85.97 & 11.576 \\
\hline
\end{tabular}

Table 6. T-test results to compare participant's means scores on the self-confidence scale by gender and educational level

\begin{tabular}{lrcl}
\hline Variable & T-Value & Freedom Degrees & $\boldsymbol{\alpha}$ \\
\hline Gender & 15.805 & 498 & 0,000 \\
College level & 18.062 & 498 & 0.000 \\
\hline
\end{tabular}

